\title{
OVIPOSICIÓN Y ASPECTOS BIOLÓGICOS DEL HUEVO DE Oncometopia clarior (HEMIPTERA: CICADELLIDAE) EN Dioscorea rotundata
}

\section{OVIPOSITION AND BIOLOGICAL ASPECTS OF Oncometopia clarior (HEMIPTERA: CICADELLIDAE) EGG IN Dioscorea rotundata}

\author{
Deivys M. Alvarez ${ }^{*}$, Wendy Y. Arroyo ${ }^{1}$, Antonio M. Pérez², Javier D. Beltrán ${ }^{3}$ \\ Recibido para publicación: Noviembre 6 de 2012 - Aceptado para publicación: Diciembre 2 de 2012
}

\section{RESUMEN}

Los Cicadellidae son insectos de importancia agrícola por ser vectores de fitopatógenos. Oncometopia clarior es responsable de la transmisión del Virus del mosaico suave del ñame que causa pérdidas en la producción en los cultivos de ñame. Este estudio describe la biología del huevo del cicadélido Oncometopia clarior. Se recolectaron hembras adultas en cultivos de ñame y se confinaron en jaulas de oviposición con plantas de Dioscorea rotundata, se retiraron las hojas con posturas y se incubaron los huevos. Se encontró que la oviposición ocurre en el envés de las hojas y de forma endofítica. Los huevos fueron puestos en filas de 4 a 25 y cubiertos con brochosoma. Su tamaño fue de 2,39 $\mathrm{mm} \pm 0,1197$ de longitud y 0,53 $\mathrm{mm} \pm 0,062$ de ancho, son de forma alargada con extremos redondeados. La duración del periodo embrionario fue de 6,58 \pm 0,98 días.

Palabras clave: chicharrita, período embrionario, ñame.

\begin{abstract}
Cicadellidae are insects of agricultural importance because they are plant pathogens vectors. Oncometopia clarior is responsible for transmission of Yam mild mosaic virus that causes yield losses in yam crops. This study describes the egg biology of leafhopper Oncometopia clarior. Adult females were collected in yam crops and confined in oviposition cages with Dioscorea rotundata plants, the leaf with postures were removed and the eggs were incubated. Oviposition occurs on the underside of the leaf in endophytic form. The eggs were laid in rows of 4 to 25 and these were covered with brochosome. Their size was $2.39 \mathrm{~mm} \pm 0.1197$ in length and $0.53 \mathrm{~mm} \pm 0.062$ width; they showed an elongated shape with rounded ends. The duration of embryonic period was $6.58 \pm 0.98$ days.
\end{abstract}

Key words: leafhopper, embryonic period, yam.

'Biólogos candidatos a Maestría en Biología. E-mail: deivysalvarez@gmail.com

${ }^{2}$ Docente MSc Entomología.

${ }^{3}$ Docente PhD Fitopatología.

Universidad de Sucre. Laboratorio de Entomología. Grupo de Investigación en Biotecnología Vegetal. Cra 28 No 5-267. Tel: 2821240 Ext. 255 y 256. Sincelejo, Colombia. 


\section{INTRODUCCIÓN}

El ñame (Dioscorea spp.) es cultivado en las regiones pluviosas tropicales y subtropicales del mundo. En Colombia, este cultivo reviste gran importancia socioeconómica para la Región Caribe; siendo los departamentos Bolívar, Córdoba y Sucre los de mayor producción; donde es utilizado para consumo en fresco y para exportación (Álvarez 2000). Entre las enfermedades limitantes del cultivo se encuentra la virosis ocasionada por el Virus del mosaico suave del ñame (YMMV) (Munford y Seal 1997), también Ilamado Virus de Dioscorea Alata (DAV) (Odu et al. 1999). Este virus es transmitido, en Colombia, por algunas especies de la familia Cicadellidae y afecta la producción por la disminución en el tamaño y calidad de los tubérculos (Alvarez et al. 2011a, 2011b).

Los cicadélidos son insectos también conocidos como chicharritas o saltahojas (Freytag y Sharkey 2002), de importancia agrícola debido a que son vectores eficientes de fitopatógenos; además pueden causar daños directos en las plantas al alimentarse de la savia de los tejidos, lo cual resulta en un debilitamiento general (Nielson 1985). Entre los Cicadellidae más importantes se encuentran los del género Oncometopia con especies como Oncometopia facialis responsable de la transmisión de la bacteria Xylella fastidiosa causante de la Clorosis Variegada de los Cítricos (Roberto et al. 1996) y Oncometopia sp. vector del Virus del mosaico suave del ñame en Dioscorea rotundata (Alvarez et al. 2011a). Debido a la importancia de Oncometopia sp. y su incidencia en cultivos de ñame (Dioscorea alata y Dioscorea rotundata) en la Región Caribe de Colombia, se propuso estudiar la oviposición y el período embrionario de Oncometopia clarior como aspecto importante en la biología de vectores.

\section{MATERIALES Y MÉTODOS}

Se realizaron colectas de hembras adultas de Oncometopia clarior (Figura 1), mediante captura manual y aspirador bucal, en cultivos de Dioscorea rotundata var. "Botón" ubicados en el corregimiento de La Siria del municipio Tolú Viejo, (Sucre, Colombia). Los insectos se trasladaron, al laboratorio de entomología de la Universidad de Sucre, utilizando bolsas de muselina de $25 \mathrm{~cm}$ de largo y $15 \mathrm{~cm}$ de ancho, y en cuyo interior se introdujo un pequeño segmento de tallo con hojas como fuente de alimento. Adicionalmente, individuos machos y hembras se enviaron al Laboratorio Nacional de Diagnostico Fitosanitario del ICA, para su determinación taxonómica.

Para facilitar las colectas de los huevos, los especímenes se confinaron en plantas de $D$.

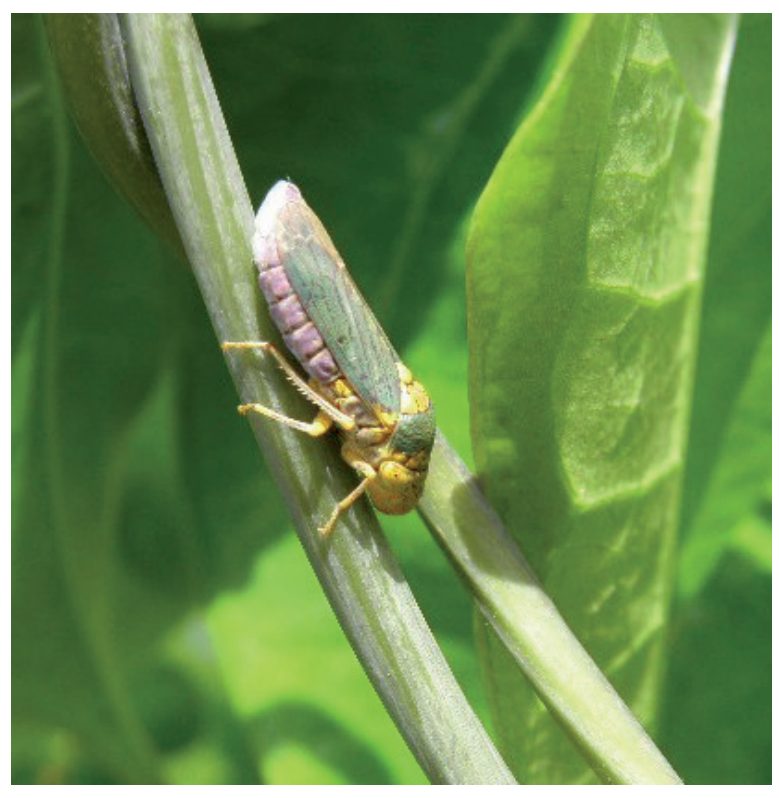

Figura 1. Oncometopia clarior en tallo de $D$. rotundata var "Botón". 
rotundata var. "Botón" utilizando cámaras de oviposición formadas con macetas plásticas y jaula cilíndrica cubierta con una caperuza de muselina. Se realizaron revisiones diarias y se retiraron las hojas de las plantas donde se encontraron posturas. Los huevos se incubaron a $28^{\circ} \mathrm{C}$ en cajas petri con papel absorbente humedecido con $\mathrm{NaOCl}$ al $2 \%$. Se llevó el registro del lugar de oviposición (haz ó envés de la hoja), el número de huevos por postura fue agrupado en intervalos de clase, se promedió el largo y ancho de los huevos con ayuda de un estereoscopio con micrómetro, se describieron los cambios morfológicos y se promedió la duración del período embrionario. Los valores promedios y su desviación estándar se obtuvieron con el programa Excel 2007.

\section{RESULTADOS Y DISCUSIÓN}

Se informa que Oncometopia clarior es la especie referida por Alvarez et al. (2011a, 2011b) como vectora del Virus del mosaico suave del ñame en Dioscorea rotundata. El vector O. clarior se distribuye en Estados Unidos, México, Guatemala, Honduras, El Salvador, Nicaragua, Costa Rica, Panamá, Colombia y Brasil (Maes 2004), es polífaga y entre sus hospederos se encuentra Cucurbita pepo, Cucumis melo, Glycine max, Vigna unguiculata, Phaseolus vulgaris, Sesamum indicum, Zea mays, Nicotiana tabacum, Dracaena marginata,
Lantana cámara, Cyathula prostata, Laportea aestuans, Eleusine indica, Phyllanthus amarus, Coffea arabica, Jatropha curcas, Citrus sp, Dioscorea alata y Dioscorea rotundata (Alvarez et al. 2011a, 2011b; Garita-Cambronero et al. 2008; Maes 2004; Pérez 2007).

La oviposición ocurrió en las hojas y se distribuyó con mayor frecuencia en la cara abaxial; así, de 53 posturas estudiadas 47 $(86,7 \%)$ estuvieron en el envés y seis $(13,3 \%)$ en el haz. Los huevos fueron ovipositados en masa formando filas de 4 a 25, siendo las masas de 11 a 15 huevos las más frecuentes $(38,46 \%)$ (Tabla 1$)$. Todas las posturas fueron hechas de manera endofítica y cubiertas con brochosoma (Figura 2), que es una sustancia producida en los tubos de Malpighi y es excretada por el ano en varias especies de Cicadellidae. Entre las funciones que se le atribuyen se encuentran la prevención de la deshidratación, protección contra los rayos ultravioletas, protección contra depredadores y parasitoides, y actividad antimicrobial (Hix 2001; Rakitov 2002; Rakitov 2004). Estos resultados concuerdan con los de Pérez (2007), quien encontró que las hembras de $O$. clarior ovipositan en el envés de hojas sanas de D. marginata, C. prostata, Phenax sonneratii y $P$. amarus, además los huevos fueron puestos en masa y cubiertos con brochosoma. Este comportamiento también ha sido informado

Tabla 1. Número de huevos por masa ovipositados por Oncometopia clarior en D. rotundata var "Botón".

\begin{tabular}{ccccc}
\hline Intervalo de Clase & Frecuencia & $\begin{array}{c}\text { Frecuencia } \\
\text { Acumulativa }\end{array}$ & $\begin{array}{c}\text { Frecuencia } \\
\text { Relativa }\end{array}$ & Porcentaje (\%) \\
\hline $1-5$ & 5 & 5 & 0,1923 & 19,23 \\
$6-10$ & 6 & 11 & 0,2308 & 23,08 \\
$11-15$ & 10 & 21 & 0,3846 & 38,46 \\
$16-20$ & 3 & 24 & 0,1154 & 11,54 \\
$21-25$ & 2 & 26 & 0,0769 & 7,69 \\
\hline
\end{tabular}




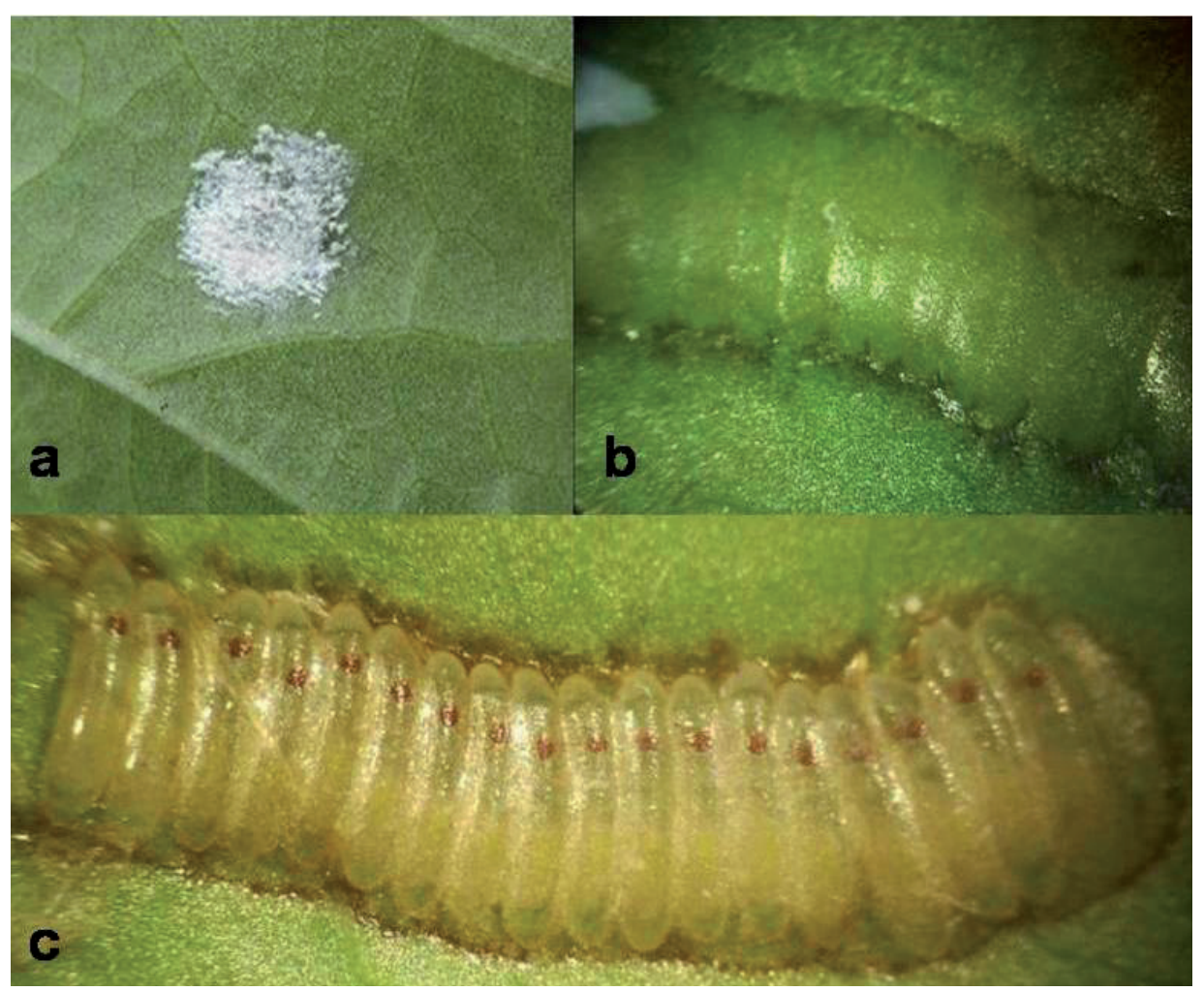

Figura 2. Huevos de Oncometopia clarior. a. Postura cubierta con brochosoma, b. Postura sin brochosoma y c. Detalle de los huevos sin brochosoma y sin la epidermis foliar.

para otras especies de cicadélidos como Oncometopia facialis, Dilobopterus costalimai y Homalodisca ignorata quienes ovipositan de forma endofítica en el envés de las hojas de Citrus sinensis, sin embargo solo $O$. facialis y H. ignorata cubren los huevos con brochosoma (Almeida y Lopes 1999; Paiva et al. 2001).

Por otra parte, los huevos tuvieron una longitud de 2,39 $\mathrm{mm} \pm 0,1197$ y 0,53 $\mathrm{mm} \pm 0,062$ de ancho, son de forma alargada y con extremos redondeados. Dos días después de la oviposición los huevos siguieron sin sufrir cambios apreciables en su coloración y forma, sin embargo, los bordes del área foliar alrededor de la postura comenzaron a necrosarse. A los tres días, se observaron puntos rojos bastante próximos a su polo ecuatorial correspondientes a los futuros ojos (Figura 2); estas puntuaciones oculares se hicieron, cada día, más conspicuas y migraron hacia el polo cefálico hasta ubicarse a ambos lados de la futura cabeza. La mitad caudal del huevo se tornó amarilla y cinco días después la parte anterior se proyectó debido a la formación del clípeo. Finalmente, el período embrionario tuvo una duración de 6,58 \pm 0,98 días.

\section{CONCLUSIONES}

Las hembras del cicadélido Oncometopia clarior prefirieron el envés de las hojas para ovipositar. Los huevos fueron puestos en masa, de forma endofítica y cubiertos con brochosoma. El período embrionario fue de $6,58 \pm 0,98$ días. 


\section{REFERENCIAS}

Almeida, R. y Lopes, J. 1999. Desenvolvimento de imaturos de Dilobopterus costalimai Young, Oncometopia facialis (Signoret) e Homalodisca ignorata Melichar (Hemiptera: Cicadellidae) em citros. Anais da Sociedade Entomológica do Brasil 28:179-182.

Álvarez, A. 2000. Prácticas agronómicas para el cultivo del ñame. En: Guzmán, M. y Buitrago, G. (ed). Ñame: producción de semilla por biotecnología. Unibiblos. Bogotá, Colombia, p33-39.

Alvarez, D., Pérez, A., Díaz, J., Maestre, M. y Beltrán, J. 2011a. Transmisión del Virus del mosaico suave del ñame a Dioscorea rotundata (Dioscoreaceae) por Oncometopia sp (Cicadellidae). Revista Colombiana de Entomología 37:77-79.

Alvarez, D., Pérez, A., Díaz, J., y Beltrán, J. 2011b. Detección del Virus del mosaico suave del ñame mediante IC-RT-PCR en cicadélidos, Rhynchosia minima y Dioscorea rotundata. Temas Agrarios 16:36-40.

Freytag, F. y Sharkey, M. 2002. A preliminary list of the leafhoppers (Homoptera) of Colombia. Revista Biota Colombiana 3(2):235-283.

Garita-Cambronero, J., Villalobos, W., Godoy, C. y Rivera, C. 2008. Diversidad de Cicadélidos y Clastoptéridos
(Hemiptera) en tres zonas productoras de café afectadas por Xylella fastidiosa Wells et al. en Costa Rica. Neotropical Entomology 37(4):436-448.

Hix, R. 2001. Egg-laying and brochosome production observed in glassy-winged sharpshooter. California Agriculture 50:19-22.

Maes, J. 2004. Insectos asociados a algunos cultivos tropicales en el Atlántico de Nicaragua. Parte XXIII. Crotalaria (Crotalaria sp., Fabaceae). Revista Nicaragüense de Entomología 64:1-75.

Munford, R. y Seal, S. 1997. Rapid single tube immunocapture RT-PCR for the detection of two yam potyviruses. Journal of Virological Methods 69:73-79.

Nielson, M. 1985. Leafhopper systematic. In: Nault, L. and Rodriguez, J. (Ed). The Leafhoppers and planthoppers. John Wiley \& Sons. New York, p11-39.

Odu, B., Hughes, J., Shqyinka, S. y Dongo, L. 1999. Isolation, characterization and identification of Potyvirus from Dioscorea alata L. (water yam) in Nigeria. Annals of Applied Biology 134:65-71.

Paiva, P., Benvenga, S. y Gravena, S. 2001. Aspectos biológicos das cigarrinhas Acrogonia gracilis (Osborn), Dilobopterus costalimai Young e Oncometopia facialis (Signoret) (Hemiptera: Cicadellidae) em Citrus sinensis L. Osbeck. Neotropical Entomology 30:25-28. 
Pérez, G. 2007. Evaluación de comportamiento de Oncometopia clarior (Walker) (Hemíptera: Cicadellidae) ante especies vegetales asociadas al cultivo Dracaena marginata (Lamarck) y su preferencia a diversos regímenes de fertilización. Tesis Maestría en Agricultura Ecológica. Centro Agronómico Tropical de Investigación y Enseñanza. Costa Rica.

Rakitov, R. 2002. What are brochosomes for? An enigma of leafhoppers (Hemiptera, Cicadellidae). Denisia 4:411-432.
Rakitov, R. 2004. Powdering of egg nests with brochosomes and related sexual dimorphism in leafhoppers (Hemiptera: Cicadellidae). Zoological Journal of the Linnean Society 140:353-381.

Roberto, S., Coutinho, A., Lima, J., Miranda, V. and Carlos, E. 1996. Transmissão de Xylella fastidiosa pelas cigarrinhas Dilobopterus costalimai, Acrogonia terminalis e Oncometopia facialis em citros. Fitopatologia Brasileira 21:517-518. 